\title{
THE USE OF XENOGRAFTING TO EVALUATE THE REMYELINATING POTENTIAL OF GLIAL CELL CULTURES
}

\author{
M. P. TARGETT and W. F. BLAKEMORE \\ Cambridge
}

\begin{abstract}
SUMMARY
Experiments in rodents have shown a potential role for glial cell transplantation as a means of influencing repair in the central nervous system of man. A crucial step in developing human therapy is to establish whether knowledge gained from studies in rodents is applicable to larger mammalian species. In order to explore this issue we examined the ability of cat glial cell cultures to remyelinate areas of ethidium-bromide-induced demyelination in the spinal cord of immunosuppressed rats and cats. Transplantation of density-gradient-isolated glial cells obtained from the forebrain of 7-day-old kittens resulted in enhanced oligodendrocyte remyelination in the rat but failed to enhance oligodendrocyte remyelination in the cat. The feasibility of enhancing oligodendrocyte remyelination in the cat lesion was demonstrated by transplanting a rat culture containing a high proportion of cells of the oligodendrocyte lineage. Tissue culture of the density-gradient-isolated cell preparations suggested that the failure of the kitten glial preparation to enhance oligodendrocyte remyelination in the cat was most probably due to its poor oligodendrocyte-generating capacity. However, our lack of understanding of the biology of feline glial cells precludes a full understanding of these experiments.
\end{abstract}

The neurons of the central nervous system (CNS) are enclosed within an astrocytic environment. This glial environment has a distinct surface beneath the meninges and around blood vessels where the astrocyte surface which constitutes the boundary is coated by basement membrane to form a structure termed the glia limitans. Within the astrocyte-bounded CNS, axons are myelinated by oligodendrocytes; as axons leave the CNS they become associated with Schwann cells. In normal circumstances there is a clear separation of the two forms of glial-axonal

Correspondence to: M. P. Targett, MS Research Group, MRC Cambridge Centre for Brain Repair, Department of Clinical Veterinary Medicine, University of Cambridge, Madingley Road, Cambridge CB3 OES, UK. environment at this transition zone between the peripheral nervous system (PNS) and CNS. Following damage to the CNS glial environment this orderly situation becomes disrupted. The glia limitans does not necessarily re-form at its original location, the consequence of which is that Schwann cells encroach into areas previously occupied by astrocytes and oligodendrocytes. With the advent of glial cell transplantation as an experimental tool it has been possible to study in detail how the various glial cells interact with one another to reconstruct glial environments. These studies have demonstrated the specific role of various glial cell types in reconstructing CNS glial environments and in particular the close interaction between astrocytes and oligodendrocytes that is required to prevent Schwann cells from remyelinating CNS axons and thereby re-establishing a new PNS-CNS boundary. ${ }^{1-3}$

With our increasing understanding of the ground-rules for the reconstruction of CNS glial environments in the rat it is now possible to address the question of how clinical situations such as multiple sclerosis (MS), where inherent reconstruction is incomplete, could be improved by transplantation strategies. Particularly encouraging in this context is the recent demonstration that transplanted oligodendrocyte progenitors will remyelinate demyelinated axons within non-repairing CNS lesions in adult rats. ${ }^{4}$ Furthermore, progenitor transplants result in more extensive myelination than mature oligodendrocyte transplants in hypomyelinated recipients. ${ }^{5}$ However, before transplantation emerges as a viable therapy a number of key issues need to be resolved. For example, will transplanted cells remyelinate chronically demyelinated axons such as those found in MS plaques and if so would they restore function? And to what extent is knowledge acquired in small rodents applicable to larger mammalian species and eventually man? ${ }^{1}$

In an attempt to address this last issue we have undertaken a series of experiments in which various glial cell 
preparations have been injected into areas of demyelination in cats and rats.

\section{METHODS}

\section{Isolation of Glial Cell from Postnatal 7-day-old Cat Forebrain}

Immediately after euthanasia with an intraperitoneal injection of pentobarbitone sodium the forebrain of a 7-day-old kitten was removed and placed in cold Eagle's minimal essential medium containing $20 \mathrm{mM}$ Hepes (MEM/HEPES) and then transferred into calcium- and magnesium-free Hanks buffered salt solution (Hanks) for removal of the meninges and choroid plexi using a dissecting microscope. The tissue was chopped roughly into $1 \mathrm{~mm}^{3}$ blocks and digested with trypsin $(0.25 \%)$ and DNase $(50 \mu \mathrm{g} / \mathrm{ml})$ in Hanks for 45 minutes. The trypsin was inactivated by the addition of $20 \%$ by volume fetal calf serum and the tissue fragments sedimented and resuspended in Dulbecco's modified Eagle's medium (DMEM) containing $0.6 \%$ glucose. The tissue was triturated and filtered (150 and $80 \mu \mathrm{m}$ mesh size) and placed onto a $25 \%$ Percoll density gradient and centrifuged at 22000 r.p.m. for 45 minutes. The entire layer between the myelin debris band and the red cell band was harvested. The Percoll was removed by repeated sedimentation and resuspension in MEM/HEPES medium. The cells were either prepared directly for transplantation, or plated onto poly-d-lysine coated tissue culture flasks at a density of $10^{5} \mathrm{cells} / \mathrm{cm}^{2}$. The cells were incubated under $5 \% \mathrm{CO}_{2}$ at $37{ }^{\circ} \mathrm{C}$ in modified DMEM containing $10 \%$ fetal calf serum, $80 \%$ of which was replaced weekly.

Cell cultures were immunostained using a panel of antibodies normally used to characterise rodent glial cell cultures, where $\mathrm{O} 1$ identifies cells committed to become oligodendrocytes, ${ }^{6} \mathrm{O} 4$ identifies proligodendrocytes and oligodendrocytes, ${ }^{7}$ A2B5 identifies O-2A progenitors and type 2 astrocytes, ${ }^{8}$ and GFAP identifies astrocytes. For immunostaining, $1 \mathrm{~cm}^{2}$ areas of the tissue culture plastic were marked out with a hydrophilic marker pen (DAKO) and $\mathrm{O} 1, \mathrm{O} 4$ or $\mathrm{A} 2 \mathrm{~B} 5$ primary mouse antibodies applied to individual areas for 30 minutes at $37^{\circ} \mathrm{C}$. The areas were then washed with Hanks medium and fixed with $4 \%$ paraformaldehyde in phosphate-buffered saline (PBS). Secondary anti-mouse IgM antibody conjugated to fluorescein was then applied. After permeabilisation of the cells with $0.03 \%$ Nonidet P40 in PBS, primary antibody to GFAP (DAKO) was applied to all the areas and a secondary antirabbit antibody conjugated to rhodamine applied. Finally all the selected areas were stained with bisbenzimide $\mathrm{H}-3325810 \mu \mathrm{g} / \mathrm{ml}$ to visualise nuclei. Areas within the triple-labelled regions were then selected at random and photographed under phase contrast and fluorescence illumination with three filter sets appropriate for demonstrating the three fluorescence reagents used. The four photographs for each field were overlaid with a grid and the percentage of cells staining with each antibody determined. The cell culture analysis was carried out at the time of each transplantation and perfusion.
Examination of the Remyelinating Potential of the Cat Glial Cells in X-irradiated Ethidium Bromide Lesions in the Rat

Cells were injected into demyelinating lesions made in the locally X-irradiated spinal cord of immunosuppressed rats. Such lesions have no repair capacity and thus any repair seen following the injection of cells can be related to the introduced cells. In order to suppress host repair responses the spinal cord between T11 and L2 was $\mathrm{X}$-irradiated with $40 \mathrm{G}$ using previously documented methods. ${ }^{9}$ Three days later $1 \mu \mathrm{l}$ of $0.1 \%$ ethidium bromide (EB) was injected into the dorsal columns at L1 and a further 3 days later $1 \mu \mathrm{l}$ of cell suspension that had been in culture for $0,7,14$ or 21 days was injected into the areas of spinal cord previously injected with EB in groups of 6 rats. Four animals in each group were maintained on cyclosporin $(15 \mathrm{mg} / \mathrm{kg}$ per day by subcutaneous injection) while 2 animals received no cyclosporin. Each group of rats was maintained for 21 days and then perfused with $4 \%$ glutaraldehyde in phosphate buffer and $1 \mathrm{~mm}$ transverse slices taken through the lesion area for routine processing into resin. Sections $1 \mu \mathrm{m}$ thick were cut from the resin blocks and stained with alkaline toluidine blue. Some sections were stained with GFAP antibodies following removal of resin and selected areas trimmed and examined by electron microscopy.

\section{Examination of the Remyelinating Potential of Transplanted Glial Cells in Ethidium Bromide Lesions in the Cat}

To create areas of demyelination $2 \mu \mathrm{l}$ of $0.1 \%$ EB was injected into the dorsal columns using previously described methods. ${ }^{11}$

To examine the ability of glial cell cultures to enhance oligodendrocyte remyelination $2 \mu \mathrm{l}$ of cell suspension at a cell density of $6 \times 10^{4} / \mu \mathrm{l}$ was injected into the lesion 3 days after injecting EB. Animals were immunosuppressed with cyclosporin $(15 \mathrm{mg} / \mathrm{kg}$ per day in divided oral doses) and then killed and examined by the same methods used for the rats 18 days after transplantation.

\section{RESULTS}

\section{Density-Gradient-Isolated Cat Glial Preparations Contain Cells that Remyelinate Demyelinated Rat Axons}

Sixty per cent of the density-gradient-isolated (DGI) cat cells stained with the $\mathrm{O} 4$ antibody. When transplanted into inherently non-remyelinating X-irradiated EB lesions made in rats, remyelination was seen only in animals which received immunosuppression, indicating that the observed remyelination was being carried out by the transplanted cells. ${ }^{10}$ In some sections up to $80 \%$ of the axons were surrounded by thin myelin sheaths characteristic of oligodendrocyte remyelination and the mean percentage of oligodendrocyte remyelination for all sections examined was $30 \%$. The remyelinated axons were present within a fine network of astrocytic processes (Figs. 1-3). 

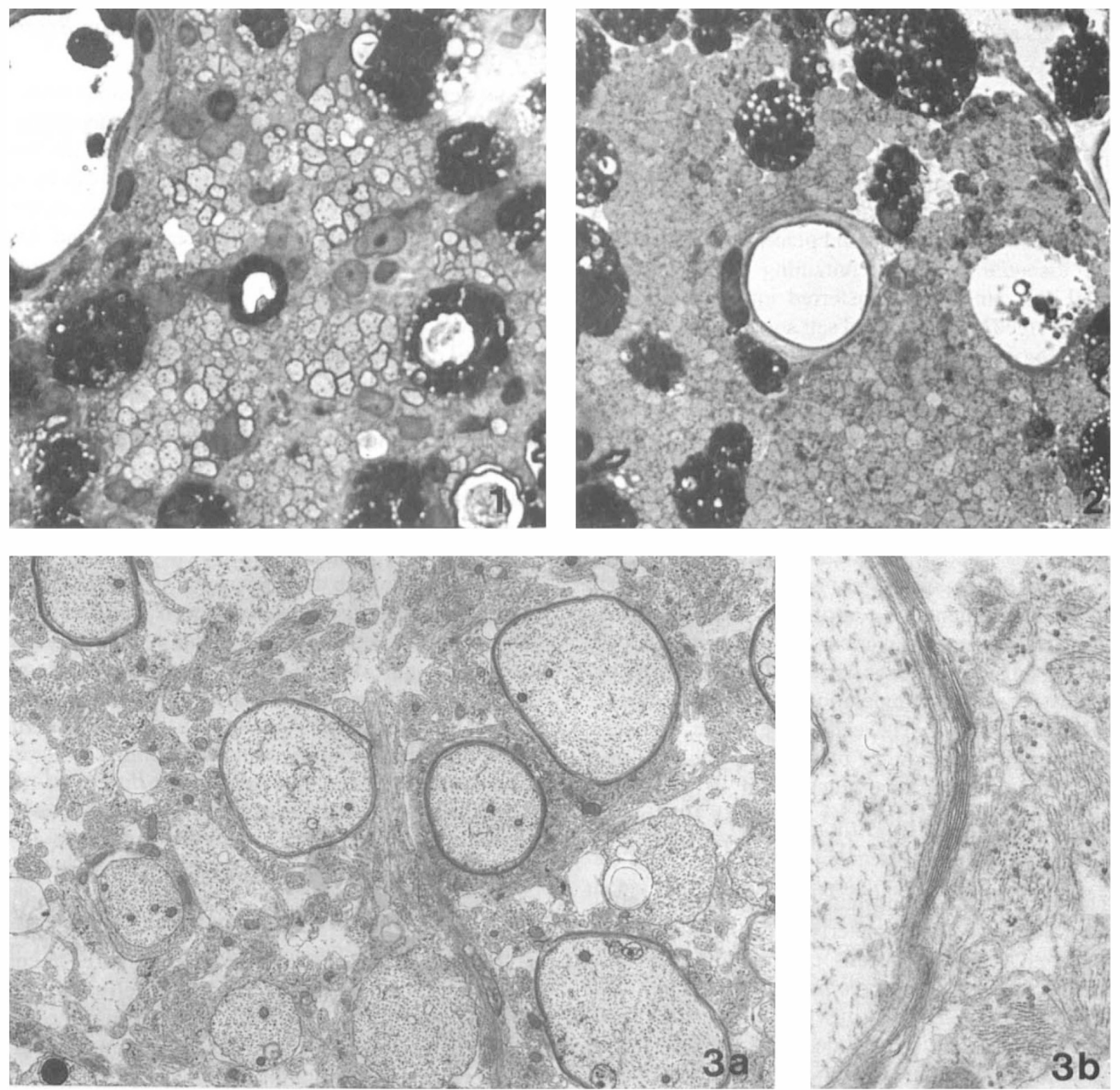

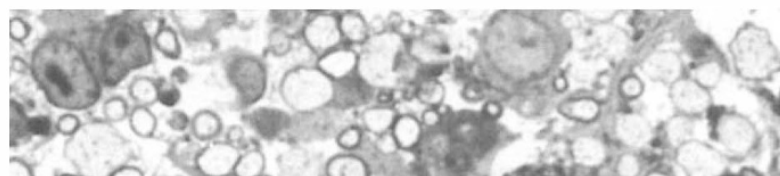
2000 abo. 4 a

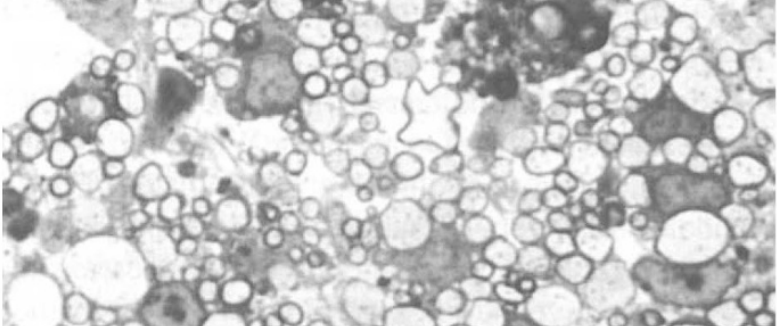

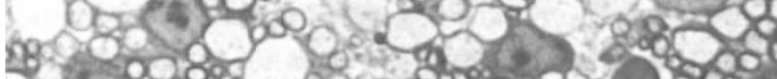

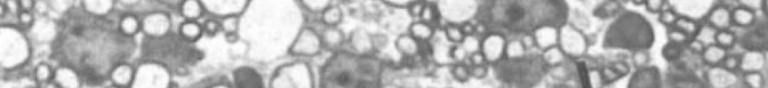

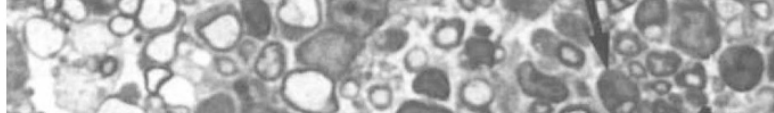
? 00 o 000 o

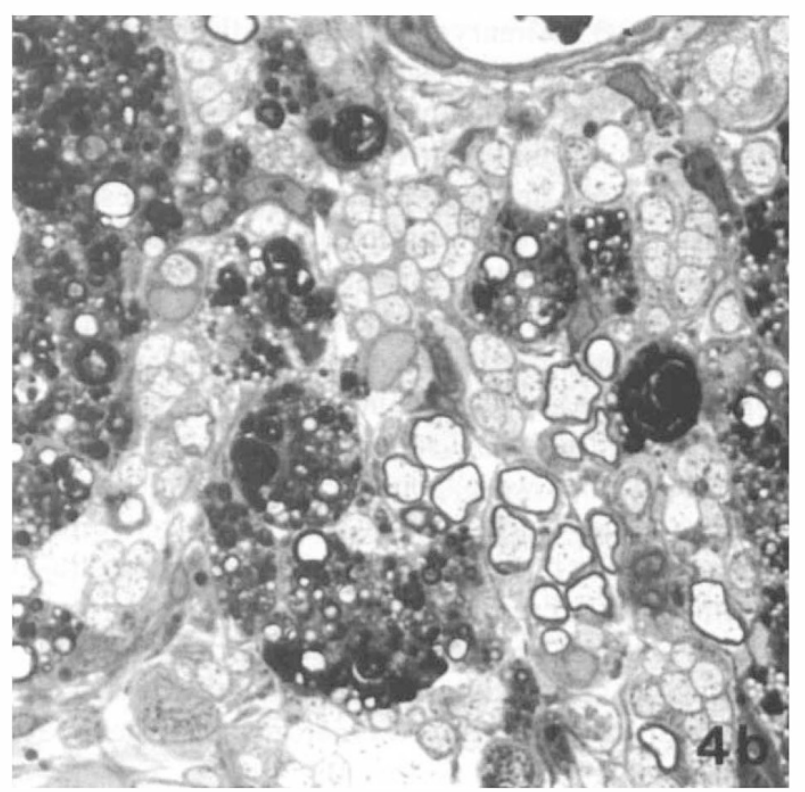


Table I. Summary of the results of transplanting a rat glial cell suspension rich in cells of the oligodendrocyte lineage into demyelinated lesions in the cat dorsal columns

\begin{tabular}{lcccc}
\hline Transplant & Immunosuppressed & $\begin{array}{c}\text { Oligodendrocyte } \\
\text { remyelination }\end{array}$ & $\begin{array}{c}\text { Schwann cell } \\
\text { remyelination }\end{array}$ & $\begin{array}{c}\text { Evidence of } \\
\text { rejection }\end{array}$ \\
\hline Medium & - & Absent & Present & Absent \\
Rat oligodendroglia & - & Absent & Present & Present \\
Rat oligodendroglia & + & Present & Present & Absent \\
\hline
\end{tabular}

Two animals were injected with medium; 4 animals were injected with rat glial cells, 2 of which received immunosuppression.

Only a small number, less than $5 \%$, of axons were remyelinated by Schwann cells.

\section{Cat Glial Cell Preparations Which Resulted in Remyelination in the Rat Fail to Enhance Oligodendrocyte Remyelination in Ethidium Bromide Lesions in the Cat}

As the results of the above experiment indicated that the DGI glial cell preparation had the potential to generate oligodendrocytes when transplanted into areas of demyelination in the rat, the cell preparation was injected into EB lesions made in the spinal cord of four immunosuppressed cats. The EB lesion in the cat is spontaneously remyelinated mainly by Schwann cells as a consequence of the extensive EB-induced damage to astrocytes. ${ }^{11}$ Following the injection of the DGI cell suspension no evidence of

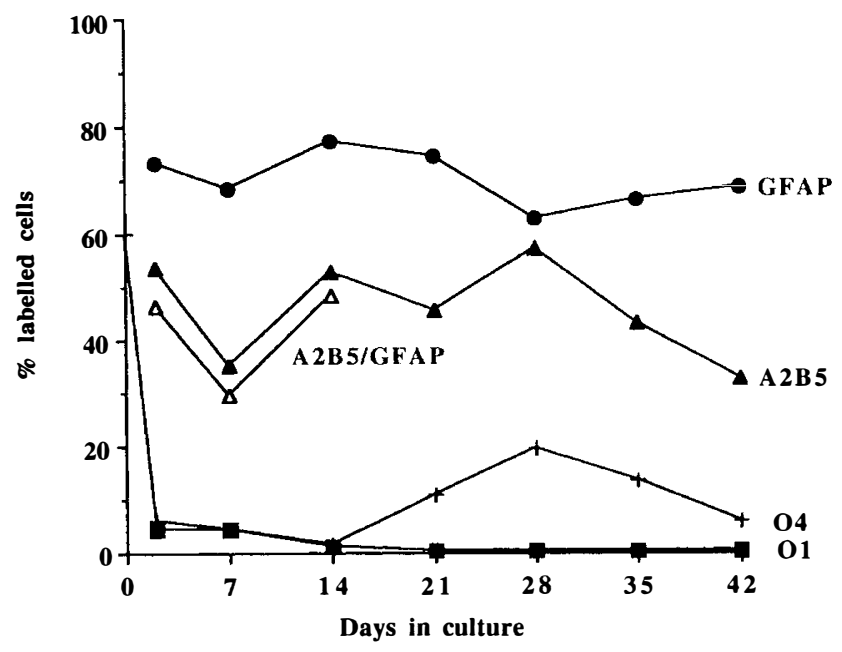

Fig. 5. The percentage of cells within the culture that were stained positively with each antibody during the time course of the experiment. enhanced oligodendrocyte remyelination was observed in any animal examined 18 days after transplantation.

\section{Rat Glial Cell Preparations Which Enhance Remyelination in the Rat also Enhance Oligodendrocyte Remyelination when Transplanted into Demyelinating Lesions in the Cat}

To test whether the failure to observe oligodendrocyte remyelination following the transplantation of the DGI cat glial cells into the EB lesion in the cat was in any way related to some property of the lesion which inhibited oligodendrocyte remyelination, rat glial cell cultures known to be capable of enhancing oligodendrocyte remyelination in the rat were injected into EB lesions made in the spinal cord of cats. A cell preparation prepared from neonatal rat forebrain containing 38\% mature O1-positive oligodendrocytes and 5\% A2B5-positive O-2A progenitors was injected into EB lesions in 4 cats. Two of the animals were immunosuppressed with cyclosporin, 2 received no immunosuppression, while a further 2 animals injected with medium served as controls. An area of oligodendrocyte remyelination was present in the centre of the lesion in the immunosuppressed animals (Fig. 4). No oligodendrocyte remyelination was observed at this site either in animals injected with medium alone, or in those injected with cells without immunosuppression (Table I). Taken together these results show that the remyelinated axons in the EB lesion in the cat spinal cord have been myelinated by transplanted rat oligodendrocytes - a finding which demonstrates that oligodendrocyte remyelination can be achieved in the EB lesion in the cat by transplantation of glial cells.

In an attempt to understand why the injection of DGI cells which contained a large number of $\mathrm{O} 4$-positive cells failed to enhance remyelination when injected into demyelinating lesions in the cat, the in vitro behaviour of

Figs. 1-3 (opposite). Fig. 1. Twenty-one days following transplantation of neonatal kitten forebrain density-gradient-isolated (DGI) cells into X-irradiated demyelinated lesions in the spinal cord of adult rats, remvelinated axons were seen only in animals that were maintained on immunosuppression. Oligodendrocyte remyelinated axons within the lesion are present within a network of astrocytic processes. Toluidine blue, 1 m m sections, $\times 1000$. Fig. 2 . In non-immunosuppressed rats that were transplanted with neonatal kitten forebrain DGI cells the lesion contained only demyelinated axons and debris-laden macrophages. Toluidine blue, 1 um sections, $\times 1000$. Fig. 3. (a) Electron microscopy of lesions demonstrates thinly myelinated axons in an environment of fine cell processes. $\times 7500$. (b) Higher-power examination show's the myelin has $11 \mathrm{~nm}$ periodicity typical of oligodendrocyte myelin and that the fine cell processes contain $8 \mathrm{~nm}$ intermediate filaments characteristic of astrocytes, $\times 30000$. Fig. 4 . Transplantation of a rat glial cell preparation enriched for cells of the oligodendrocyte lineage into demvelinated lesions in the cat dorsal columns produced an area of oligodendrocyte remyelination only when the animals were maintained on immunosuppression. (a) Central area of the lesion from an animal maintained on immunosuppression contains some axons remyelinated by Schwann cells (arrow), but most axons are remyelinated by oligodendrocytes. (b) Central area of the lesion from an animal that was not immunosuppressed showing demyelinated axons, Schwann cell remyelinated axons, and an absence of oligodendrocyte remyelinated axons. Toluidine blue, 1 rm sections, $\times 1000$. 

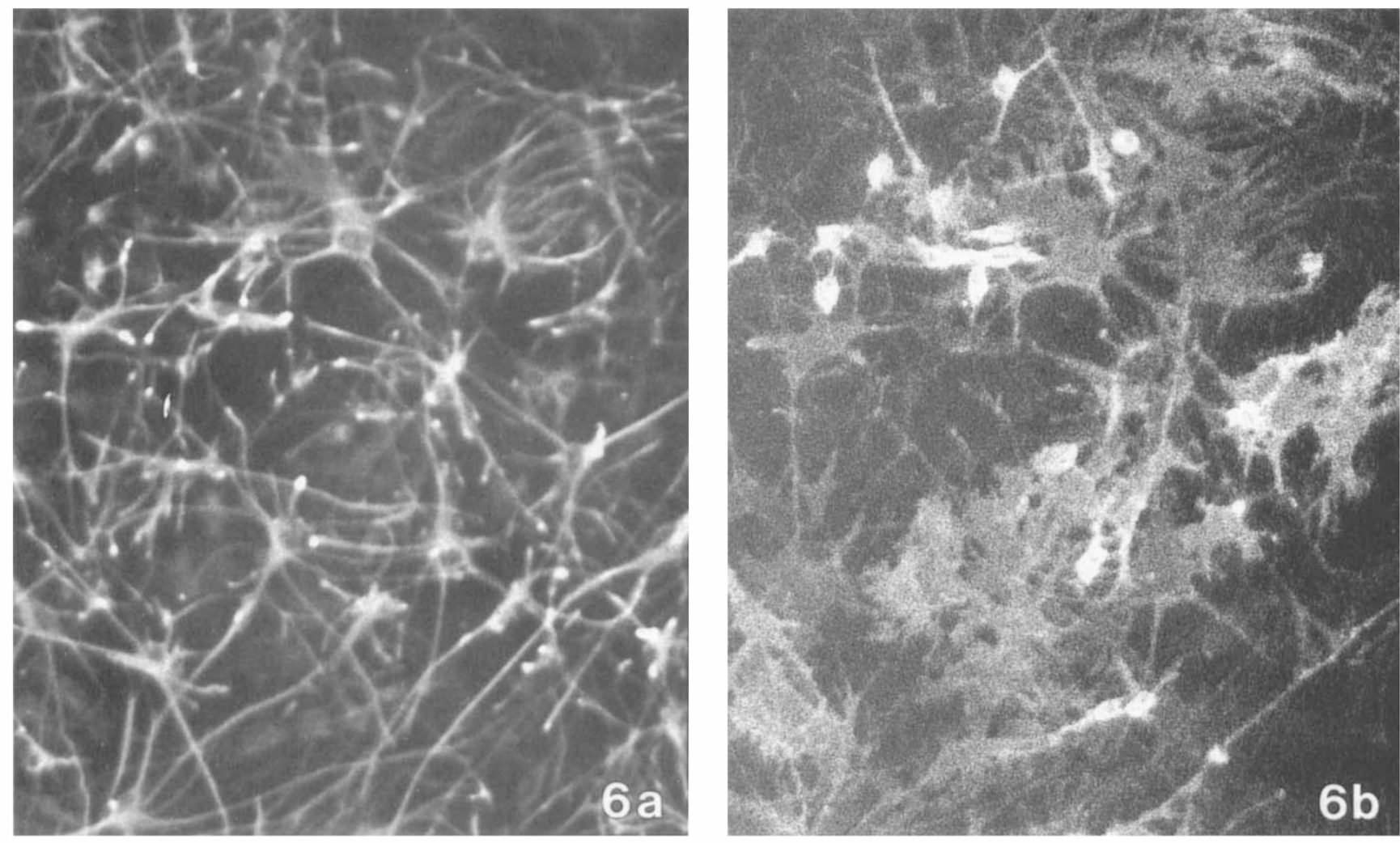

Fig. 6. Culture derived from neonatal cat DGI cells that had been maintained in vitro for 14 days, and double immunostained with antibodies against (a) GFAP and (b) A2B5. The A2B5-positive cells have a variable morphology and many are also GFAP-positive, $\times 250$.

these cells was investigated and further groups of rats with $\mathrm{X}$-irradiated EB lesions were injected with cells which had been maintained in culture for 7, 14 and 21 days.

\section{In Vitro Analysis of the Cells which Develop from the DGI Cat Preparations}

The results of the phenotypic analysis of the cultures are presented in Fig. 5. The first full analysis was performed after the cells had been allowed to adhere to the tissue culture surface for 2 days, at which time the proportion of O4positive cells had markedly declined from the $60 \%$ which stained with this antibody in cell suspension. The proportion of cells staining with $\mathrm{O} 1$ and $\mathrm{O} 4$ antibodies decreased with time. Although O1-positive cells had almost disappeared by 14 days in culture, the number of 04-positive cells was increasing by day 21 and reached a peak of nearly $20 \%$ at day 28 . The O4-positive cells seen after 14 days were small multipolar cells unlike the more oligo- dendrocyte-line cells seen during the initial stages of culture. No O1-positive cells were seen after 14 days in culture.

At all time points examined, between $60 \%$ and $80 \%$ of the cells were GFAP-positive and $36-60 \%$ of the cells were A2B5-positive (Fig. 6). Because of the high density of GFAP-positive cell processes, the overlap between A2B5 and GFAP staining was difficult to determine at all time points. However, at the earlier time points when cell density was low, over $80 \%$ of the A2B5-positive cells were also GFAP-positive. The GFAP-positive cells had long thin processes and no flat GFAP-positive cells were seen at the time points examined.

\section{Remyelination Observed Following \\ Transplantation of Cultured Glial Cells into} $X$-irradiated Ethidium Bromide Lesion in the Rat

The lesions in all the animals which did not receive immu-

Table II. The percentage of axons remyelinated by oligodendrocytes and Schwann cells within lesions in immunosuppressed animals injected with the different glial cell preparations

\begin{tabular}{|c|c|c|c|c|}
\hline \multirow{2}{*}{$\begin{array}{l}\text { Preparation } \\
\text { days in culture }\end{array}$} & \multicolumn{2}{|c|}{$\begin{array}{l}\% \text { of demyelinated axons } \\
\text { remyelinated by oligodendrocytes }\end{array}$} & \multicolumn{2}{|c|}{$\begin{array}{l}\% \text { of demyelinated axons } \\
\text { remyelinated by Schwann cells }\end{array}$} \\
\hline & Group mean & Range & Group mean & Range \\
\hline 0 & 30 & $80-0$ & 1 & $5-0$ \\
\hline 7 & 3 & $30-0$ & 5 & $15-0$ \\
\hline 14 & 0 & 0 & 3 & $20-0$ \\
\hline 21 & 3 & $15-0$ & 4 & $10-0$ \\
\hline
\end{tabular}

The percentage of axons remyelinated by each type of cell was estimated by examining five high-power fields in sections from all lesion-containing blocks. The mean percentage of each type of remyelination was then calculated for the groups of animals injected with the different cell preparations. 
nosuppression contained only debris-filled macrophages and demyelinated axons. In contrast, all the lesions in immunosuppressed animals were filled with cells; the proportion of axons surrounded by the thin myelin sheaths which characterise oligodendrocyte remyelination and those associated with Schwann cells was evaluated and the results are presented in Table II.

In the animals which received cells which had been in culture for 7 and 21 days, there was some evidence of oligodendrocyte remyelination, up to $15 \%$ of demyelinated axons being remyelinated in some sections. No oligodendrocyte remyelination was observed in the lesions injected with cells that had been in culture for 14 days. Axons remyelinated by Schwann cells occurred in small groups and were found in all animals. The number of Schwann cell remyelinated axons was greatest in the animals injected with cells that had been in culture for 7 days. The appearance of the astrocytic environment established in the lesions was similar in all animals, appearing either as a open meshwork of fine cell processes or as compact tissue in which demyelinated axons were surrounded and separated by astrocyte process.

\section{DISCUSSION}

\section{Cat Oligodendrocytes and Schwann Cells Can Myelinate Rat Axons}

That remyelination was only observed in animals which were immunosuppressed indicates that cat oligodendrocytes and Schwann cells can myelinate rat axons. This observation increases the number of examples where oligodendrocytes and Schwann cells of one species have been shown to be capable of myelinating axons of another species. ${ }^{12-15}$ A comparison of the in vitro and in vivo data shows that there may be a relationship between the number of O4-expressing cells in tissue culture and the presence of oligodendrocyte remyelination observed in the lesions following transplantation into the rat. However, the small multipolar $\mathrm{O} 4$ cells do not give rise to oligodendrocytes in tissue culture and the tissue culture fate of the $\mathrm{O} 4$ cells present in DGI preparations is unclear.

\section{Cat Astrocytes from Neonatal Forebrain Behave Differently to Rat Astrocytes}

A series of observations indicate that astrocytes prepared from the forebrain of 7-day-old kittens show different properties to astrocytes prepared from the forebrain of neonatal rats. The kitten cells formed a loose cellular matrix within the lesion while rat astrocytes prepared from similar aged animals clump together at the point of injection when transplanted into similar lesions. ${ }^{16} \mathrm{~A}$ further difference between rat and cat cells was the behaviour of the Schwann cells within the lesions. All lesions showed Schwann cell remyelination of only some of the demyelinated axons. This is in marked contrast to our previous experience following transplantation of rat cultures composed of astrocytes and low numbers of oligodendrocytelineage cells and Schwann cells which always resulted in extensive Schwann cell remyelination. ${ }^{2,3}$ These observations on the different behaviour of transplanted cat astrocytes and Schwann cells, taken with the different immunocytochemical profile and morphological appearance of the kitten astrocytes in culture, indicate that astrocytes cultured from neonatal kitten brain have different properties to those derived from neonatal rat brain. Cat glial cells have not been as extensively studied as rodent glial cells and therefore it would be premature to draw any conclusion regarding the lineage implications suggested by the current observations. It is of interest, however, that the behaviour of the kitten astrocytes shows some similarities to the in vivo behaviour of type 2 astrocytes observed following the transplantation of clonal $\mathrm{O}-2 \mathrm{~A}$ cell lines into areas of demyelination. ${ }^{17,18}$

\section{Conclusion: Transplanting Xenogeneic Cells Provides an Experimental Approach for Evaluating both the Remyelinating Potential of Cell Cultures and the Ability to Repair Experimental Lesions by Transplantation}

The work reported here illustrates how xenografting can be used to examine both the repair capacity of cell preparations and the repair potential of experimental lesions. However, our attempts to influence the repair of the cat EB lesion by transplanting a feline cell preparation have not so far been successful. The reason for this is not altogether clear. It is apparent that using only the criteria that cat cultures contain $\mathrm{O} 4$ staining cells, or that a culture can remyelinate axons when transplanted into demyelinated lesions in rats, is not sufficient to predict their behaviour when transplanted into similar lesions in the cat. Although a number of differences were noted in the properties of feline glia compared with rat glia which may have some bearing on the outcome following transplantation, our experience with rat-to-rat transplantation has shown the importance of transplanting optimal numbers of cells with an appropriate ratio of astrocytes to oligodendrocyte lineage cells when attempting to re-establish glial environments. ${ }^{2.3}$ It is possible, therefore, that the primary reason for failure to enhance oligodendrocyte remyelination in the cat may have been our failure to transplant cultures with sufficient oligodendrocyte-generating potential. In this regard it is perhaps significant that although small $\mathrm{O} 4$ multipolar cells, which might represent bipotential glial progenitors, were reappearing in culture at 21 days and reached high numbers by 28 days, no oligodendrocytes were generated in tissue culture. It may be that feline oligodendrocyte progenitors (O4-positive cells) are more susceptible to serum than rat $\mathrm{O}-2 \mathrm{~A}$ progenitors and all the cells were differentiating into astrocytes. Thus, ways to achieve a higher number of oligodendrocyte lineage cells must be sought and the possibility that feline bipotential glial progenitor cells are more sensitive to serum than rat cells needs to be investigated. The susceptibility of feline oligodendrocyte lineage cells to serum components such as complement may also need to be addressed, as autologous complement is considered to be 
toxic for oligodendrocytes. ${ }^{19}$ However, experience of transplanting rodent oligodendrocytes into situations where the blood-brain barrier is disrupted has not been a problem. It is clear that information gained from glial cell transplantation studies in one species is of value when confronted with a different species. However, without a basic understanding of the glial cell biology of that species it becomes difficult to interpret experiments of the type reported here. The progress made with glial cell transplantation in the rat was underpinned by considerable understanding of glial cell biology in that species and our experiences in the cat have highlighted the difficulties in making progress in the absence of such information.

We wish to thank Drs John Crang, Keiran McDermott and Robin Franklin for helpful discussions of this work and their contribution to this area of research. The technical expertise of $\mathbf{M}$. Stoker and J. Gilson is gratefully acknowledged, as is the financial support of this work by the Multiple Sclerosis Society of Great Britain and the Myelin Project.

Key words: Astrocytes, Cat, Demyelination, Glial cells, Oligodendrocytes, Transplantation.

\section{REFERENCES}

1. Franklin RJM. Reconstructing myelin-deficient environments in the CNS by glial cell transplantation. Semin Neurosci 1993;5:443-51.

2. Blakemore WF. Transplanted cultured type- 1 astrocytes can be used to reconstruct the glia limitans of the CNS: the structure which prevents Schwann cells from myelinating CNS axons. Neuropathol Appl Neurobiol 1992;18:460-6.

3. Franklin RJM, Crang AJ, Blakemore WF. The role of astrocytes in the remyelination of glia-free areas of demyelination. In: Seil FJ, editor. Advances in neurology, vol 59. New York: Raven Press, 1993:125-33.

4. Groves AK, Barnett SC, Franklin RJM, Crang AJ, Mayer M, Blakemore WF, Noble M. Repair of demyelinated lesions by transplantation of purified O-2A progenitor cells. Nature 1993;362:453-5.

5. Warrington AE, Barbarese E, Pfeiffer SE. Differential myelinogenic capacity of specific stages of the oligodendrocyte lineage upon transplantation into hypomyelinating hosts. J Neurosci Res 1993;34:1-13.

6. Sommer I, Schachner M. Monoclonal antibodies (O1-O4) to oligodendrocyte surfaces: an immunocytochemical study in the central nervous system. Dev Biol 1981;83:311-27.
7. Gard AL, Pfeiffer SE. Two proliferative stages of the oligodendrocyte lineage (A2B5 + O4 - ve and O4 + GalC - ve) under different mitogenic control. Neuron 1990;5:615-25.

8. Raff MC, Miller RH, Noble M. A glial progenitor cell that develops in vitro into an astrocyte or an oligodendrocyte depending on the culture medium. Nature 1983;303:390-6.

9. Blakemore WF, Crang AJ. Transplantation of glial cells into areas of demyelination in the adult rat spinal cord. In: Dunnets and Bjorklund A, editor. Neural transplantation: a practical approach. Oxford: Oxford University Press, 1992:105-22.

10. Crang AJ, Franklin RJM, Blakemore WF, Noble M, Barnett $\mathrm{SC}$, Groves A, et al. The differentiation of glial cell progenitor populations following transplantation into non-repairing CNS lesions in adult animals. J Neuroimmunol 1992;40: 243-54.

11. Blakemore WF. Ethidium bromide induced demyelination in the spinal cord of the cat. Neuropathol Appl Neurobiol 1982;8:365-75.

12. Archer DR, Cuddon PA, Duncan ID. Myelination by cryopreserved xenografts and allografts in the myelin deficient rat. Exp Neurol 1994;125:268-77.

13. Crang AJ, Blakemore WF. Remyelination of demyelinated rat axons by transplanted mouse oligodendrocytes. Glia 1991;4:305-13.

14. Gumpel M, Lachapelle F, Gransmüller A, Baulac M, BaronVan Evercooren A, Baumann N. Transplantation of human embryonic oligodendrocytes into shiverer brain. Ann NY Acad Sci 1987;495:71-85.

15. Lubetzki C, Gunsmüller A, Lachapelle F, Lombrail P, Gumpel M. Myelination of oligodendrocytes isolated from 4-6 week-old rat central nervous system and transplantation into newborn shiverer brain. J Neurol Sci 1988;88:161-75.

16. Franklin RJM, Crang AJ, Blakemore WF. The reconstruction of an astrocytic environment in glia-deficient area of white matter. J Neurocytol 1993;22:382-96.

17. Barnett SC, Franklin RJM, Blakemore WF. In vitro and in vivo analysis of a rat $\mathrm{O}-2 \mathrm{~A}$ progenitor cell line containing the temperature sensitive mutant gene of the SV40 large T antigen. Eur J Neurosci 1993;5:1247-60.

18. Trotter J, Crang AJ, Schachner M, Blakemore WF. Lines of glial precursor cells immortalised with a temperature-sensitive oncogene give rise to astrocytes and oligodendrocytes following transplantation into demyelinated lesions in the central nervous system. Glia 1993;9:25-40.

19. Compston A, Scolding N, Wren D, Noble M. The pathogenesis of demyelinating disease: insights from cell biology. Trends Neurosci 1991;14:175-82. 